\title{
LOS PRONOMBRES REFLEXIVOS CLÍTICOS COMO OPERADORES DE DESTRANSITIVACIÓN EN ESPAÑOL
}

\author{
Mario Portilla Chaves
}

\begin{abstract}
RESUMEN
Desde la perspectiva de la gramática funcional, en este artículo se describen las construcciones reflexivas, recíprocas, pasivas con se, medias, impersonales con se y antipasivas del español como el resultado de una operación de ajuste de valencia. Se propone que la finalidad fundamental de esta operación es la destransitivación de la cláusula. Semánticamente, esta destransitivación se logra fusionando en un mismo argumento al agente y al paciente (reflexivas propias, recíprocas), degradando al agente (reflexivas opcionales, reflexivas inherentes, pasivas con se, impersonales con se, medias, antipasivas) o degradando aun más al paciente (reflexivas opcionales, antipasivas). Formalmente, en todas estas construcciones, se utiliza la misma estrategia morfológica: el uso de pronombres reflexivos clíticos o de una partícula idéntica al pronombre reflexivo clítico de $3^{\circ}$ persona (se).
\end{abstract}

Palabras clave: usos de se, pronombres reflexivos, destransitivaci'on, morfosintaxis, español.

\begin{abstract}
Within the functionalist framework, this paper describes the reflexive, reciprocal, se passive, middle, se impersonal, and antipassive constructions in Spanish as a result of a valence adjusting operation. It is proposed that the main aim of this operation is clause detransitivization. Semantically, this detransitivization merges the agent and the patient in the same argument (proper reflexives, reciprocals), downplaying the agent (optional reflexives, inherent reflexives, se passives, se impersonals, middles, antipassives), or downplaying the patient even more (optional reflexives, antipassives). Structurally, the same morphological strategy is used in those clauses: the usage of clitic reflexive pronouns or a particle which is identical to the $3^{\circ}$ person clitic reflexive pronoun $(\mathrm{se})$.
\end{abstract} Key words: uses of $s e$, reflexive pronouns, detransitivization, morphosyntaxis, Spanish.

Dr. Mario Portilla Chaves. Profesor Catedrático de la Escuela de Filología, Lingüística y Literatura, Universidad de Costa Rica. San Pedro, San José, Costa Rica.

Correo electrónico: marioportilla2000@yahoo.com

Recepción: 5- 12- 2007

Aceptación: 10- 1- 2008 


\section{Roles semánticos y relaciones gramaticales}

La gramática funcional distingue claramente entre "las propiedades de la representación conceptual de las cosas y los eventos en el mundo real, y las propiedades de los elementos lingüísticos en las oraciones" (Payne 1997: 171).

Se denominan participantes a las entidades que desempeñan un cierto papel o rol en el nivel semántico. Estos roles semánticos representan relaciones conceptuales propias del mundo del mensaje. Son categorías que forman parte del contenido del mensaje y están relacionadas, en principio, con referentes del mundo extralingüístico.

Por otra parte, en el plano gramatical, se hallan las entidades lingüísticas que hacen referencia a los participantes. Estas se denominan argumentos, los cuales se relacionan directamente con el verbo de una oración. En español, así como en muchas otras lenguas, se reconocen tres argumentos: sujeto, objeto directo y objeto indirecto. Por lo general, se considera que los circunstanciales no son argumentos, pues no se relacionan directamente con el verbo. Se les llama adyacentes por su carácter más bien periférico respecto del verbo.

Los participantes desempeñan roles semánticos que se expresan como argumentos en oraciones concretas. Los roles semánticos principales asociados con los argumentos de sujeto, objeto directo y objeto indirecto son los siguientes: agente, fuerza, instrumento, experimentador, paciente, beneficiario y recibidor (cf. Comrie 1981: 52-3, Van Valin \& LaPolla 1997: 85-6).

Un agente es, prototípicamente, un instigador consciente y voluntario de una acción, un evento que produce un efecto físico visible. Generalmente, los agentes suelen gramaticalizarse ${ }^{1}$ como sujetos de una oración.

(1) Mi hijo limpió su cuarto.

(2) Ramón cortó la cebolla en rodajas.

Una fuerza es una entidad inanimada que provoca un evento, pero sin volición ni consciencia. También, una fuerza suele aparecer como sujeto.

(3) El viento cerró la puerta.

(4) El fuego consumió la vivienda.

Un instrumento es una entidad inanimada que es manipulada por un agente para llevar a cabo una acción. Los instrumentos se categorizan como sujetos, cuando se omite el agente, o como circunstanciales.

(5) La lanza atravesó su costado.

(6) El soldado atravesó su costado con la lanza.

Un experimentador es un ser que percibe una impresión sensorial o un estado interior mental o emotivo. Se gramaticalizan como sujetos o como objetos indirectos.

(7) Los niños vieron el accidente.

(8) María recordó el número de teléfono.

(9) Los cristianos odian la mentira.

(10) $\quad$ A Justo le molesta el ruido.

Un paciente es una entidad que se halla en un estado, sufre una condición o es objeto de un cambio de estado, generalmente, visible y que carece de voluntad. En español, los pacientes se categorizan como sujetos de verbos estativos y de proceso, y objetos directos de verbos de acción-proceso. 
(11) Andrés es inteligente.

(12) Los niños están contentos.

(13) María se enfermó.

(14) Se me quebró el brazo.

(15) Doña Ana cocinó pato a la pekinesa.

(16) Pedro ofendió a su vecino.

Un beneficiario es un ser animado que obtiene el fruto de la realización de algún evento. Este se gramaticaliza como un circunstancial.

(17) Traje comida para todos.

(18) Para Cristián, no hay como ir al cine.

Un recibidor es un ser animado que es el destinatario de algún objeto. Se gramaticaliza como un objeto indirecto.

(19) Roberto le vendió barato el carro a Esteban.

(20) Les traje comida a todos.

Como se ha visto, ciertos roles semánticos se relacionan, conceptualmente, de una manera más estrecha con algunos tipos semánticos de verbos.

En general, los verbos se pueden clasificar en dos grandes grupos: estativos y dinámicos (cf. Wilson 1985, Van Valin \& LaPolla 1997:83-4).

Los verbos estativos describen eventos o situaciones que implican la localización, el estado o condición, o la experiencia interior de un participante. Desde el punto de vista de la duración, los verbos estativos refieren eventos que suelen extenderse bastante en el tiempo.

(1) Hay una fiesta en casa de Sofía.

(2) Ella siempre ha tenido muy buen humor.

(3) Viviré feliz el resto de mis días.

(4) Me gusta la música instrumental.

Los verbos dinámicos describen eventos que tienden a ser más instantáneos, a extenderse limitadamente en el tiempo. Se reconocen, por lo general, tres tipos de verbos dinámicos: de proceso, de acción y de acción-proceso.

Los verbos de proceso describen un cambio de estado que ocurre en el tiempo. Normalmente, los verbos de proceso se relacionan con un solo argumento. Por lo general, pueden responder a las preguntas ¿qué pasó? o ¿qué le pasó a X?

(9) Los gemelos nacieron ayer.

(10) La pared se humedeció.

(11) Don David (se)_murió de un infarto.

(12) Se derritió el hielo.

Los verbos de acción describen eventos que son actos voluntarios o no, realizados por algún participante, pero que no implican necesariamente un paciente afectado. Aquí se incluyen, como verbos de acción, los verbos de movimiento y los que expresan funciones corporales, los cuales algunas veces son tratados como clases aparte (cf. Payne 1997: 54-6). Prototípicamente, estos verbos responden a la pregunta ¿qué hizo X?

(13) Los niños corrían en la calle.

(14) Todos cantaban alegremente. 
(15) María estaba leyendo en voz alta.

(16) El boxeador estaba sangrando mucho.

Los verbos de acción-proceso describen situaciones en las que aparecen necesariamente tanto un agente (una fuerza, un instrumento, o un experimentador) como un paciente afectado. Generalmente, estos verbos responden a dos preguntas ¿qué hizo X? y ¿qué le pasó a Y?

(17) Todos comieron postre.

(18) Ramírez no se peinó hoy.

(19) María estaba leyendo un libro de astrología.

(20) Carmen castigó a su novio.

\section{Valencia semántica y valencia gramatical}

La noción semántica de valencia se refiere al número de participantes implicados en un determinado evento expresado por un verbo. Por ejemplo, semánticamente, el verbo golpear refiere un evento que implica necesariamente dos participantes, un agente que ejecuta la acción de golpear y un paciente que es golpeado. Por su parte, el verbo caminar refiere una situación en la que está implicado solamente un participante: quien realiza el movimiento. Así, se dice que el primer verbo es bivalente, mientras que el segundo es monovalente.

Los verbos trivalentes o de valencia 3, por lo general, implican la presencia de un agente, un paciente y un beneficiario o recibidor, como en el caso de los verbos regalar, enviar, vender. Prototípicamente, se trata de verbos de acción-proceso.

Los verbos bivalentes o de valencia 2 implican normalmente un agente y un paciente. Algunos ejemplos de estos son los verbos de acción-proceso matar, golpear, masticar, sembrar.

Los verbos monovalentes o de valencia 1 implican un agente cuando se trata de verbos de acción como cantar, hablar, llorar, pero un paciente cuando son verbos de estado o de proceso como vivir, despertar, crecer, explotar.

Existen, en español, verbos nulovalentes o de valencia 0 que, prototípicamente, no contemplan la presencia de ningún participante. Se trata de verbos de estado o de acción que expresan fenómenos naturales como llover, tronar, amanecer, que gramaticalmente son verbos unipersonales.

Por otro lado, la noción gramatical de valencia hace referencia al número de argumentos presentes en una determinada cláusula. Estos argumentos se definen como aquellos elementos nominales que establecen una relación sintáctica con el verbo en la oración. Así, por ejemplo, según la oración dada, el mismo verbo golpear, que semánticamente es bivalente, puede ser gramaticalmente o bien bivalente como en el caso de decir María golpeó a Juan, o bien monovalente como en la oración, Juan fue golpeado. En la primera oración, las nociones semánticas de agente y paciente se corresponden con las nociones gramaticales de sujeto y objeto, respectivamente. En la segunda oración, la operación morfosintáctica, conocida como voz pasiva, ha reducido la valencia gramatical de un verbo semánticamente bivalente, omitiendo la mención del agente y presentando al paciente de la acción como sujeto.

Las operaciones morfosintácticas de ajuste de valencia pueden tanto reducir la valencia semántica como aumentarla. 


\section{Las cláusulas transitivas}

Desde el punto de vista semántico, las cláusulas transitivas codifican prototípicamente eventos que son expresados por verbos dinámicos de acción-proceso. Por ello, estas involucran también dos participantes: un agente y un paciente. El agente corresponde a un participante que es el controlador del evento y que actúa con consciencia y voluntad. Por su parte, el paciente es un participante inactivo, que sufre el efecto del evento expresado por el verbo.

También, en las cláusulas transitivas es posible encontrar, en lugar de agentes, otros participantes afines a estos, como una fuerza, un experimentador o un instrumento. En estas construcciones, pueden aparecer también otras clases de verbos, no tan prototípicamente de acción-proceso, especialmente verbos de acción y de proceso.

(1) Pedro mastica tabaco. (Pedro = agente) (verbo de acción-proceso)

(2) El tornado destechó diez casas. (el tornado = fuerza) (verbo de acción-proceso)

(3) Yo ya vi esa película. (yo = experimentador) (verbo de acción)

(4) El teléfono despertó al bebé. (el teléfono = instrumento) (verbo de proceso)

Desde una perspectiva pragmática, en la prototípica voz activa, el participante mayormente topicalizado corresponde al sujeto de la cláusula. Normalmente, en español, los agentes, y otros participantes afines, son categorizados como sujetos y los pacientes como objetos directos de la cláusula. Los siguientes ejemplos ilustran las correspondencias de estas relaciones.

(5) Los milicianos $\mathrm{S}$ renovaron sus ataques OD.

(6) Enrique $\mathrm{S}$ encendió la luz OD.

(7) Ahí puede comprar los refrescos oD. (sujeto $=$ pronominalización cero $^{2}$ )

(8) Los gatos $\mathrm{S}$ cazan ratones $\mathrm{OD}$.

En todas las oraciones anteriores, la valencia semántica y la gramatical son equivalentes. Por un lado, todos los verbos son de acción-proceso. Son verbos de valencia 2, los cuales presuponen la presencia de dos participantes: un agente y un paciente. Por otro lado, en las cláusulas, aparecen tanto un sujeto como un objeto directo, los cuales representan respectivamente a los participantes mencionados. Por lo tanto, hay también dos argumentos en la cláusula.

\section{Las operaciones de ajuste de valencia}

Estas operaciones representan un ajuste de valencia. Son estrategias lingüísticas que son utilizadas, en las lenguas del mundo, para resolver la falta de congruencia entre las nociones semántica y gramatical expresadas en el discurso. Como se ha dicho, en las cláusulas transitivas la valencia semántica y la gramatical se corresponde de forma equivalente. Sin embargo, en múltiples ocasiones, el agente de una cláusula (y otros participantes afines) no es categorizado como sujeto. De igual manera, el paciente puede no ser gramaticalizado como objeto directo.

El propósito de la presente investigación es mostrar que las diferentes construcciones reflexivas, recíprocas, pasivas con se, impersonales con se, medias y antipasivas, en español, constituyen estrategias de disminución de la valencia, cuyo objetivo principal es la destransitivación de la cláusula.

La destransitivación ocurre porque estas operaciones morfosintácticas permiten fusionar en un mismo argumento al agente y al paciente (reflexivas propias, recíprocas), 
degradar al agente (reflexivas opcionales, reflexivas inherentes, pasivas con se, impersonales con se, medias, antipasivas) o degradar al paciente (reflexivas opcionales, antipasivas).

Desde el punto de vista formal, hay que destacar que, en principio, todas estas construcciones tienen en común el hecho de contener pronombres personales reflexivos, los cuales funcionan precisamente como marcadores de destransitivación en la oración.

Los reflexivos son pronombres clíticos idénticos a los pronombres personales no reflexivos en algunas de las personas gramaticales ( $1^{\circ}$ y $2^{\circ} a$ personas), pero distintos en otras ( $2^{\circ} b$ y $3^{\circ}$ personas) (cf. tablas 3.1 y 3.2 ).

Tabla 3.1. Pronombres reflexivos clíticos

\begin{tabular}{lccc}
\hline & & singular & plural \\
\hline $\mathbf{1}^{\mathbf{0}} \mathbf{p}$ & & me & nos \\
$\mathbf{2}^{\mathbf{a}} \boldsymbol{a} \mathbf{p}$ & tú/vos & te & os \\
$\mathbf{2}^{\mathbf{o}} \mathbf{p}$ & usted & se & se \\
$\mathbf{3}^{\mathbf{0}} \mathbf{p}$ & & se & se \\
\hline
\end{tabular}

Tabla 3.2. Pronombres personales clíticos no reflexivos

\begin{tabular}{lccc}
\hline & & singular & plural \\
\hline $\mathbf{1}^{\mathbf{o}} \mathbf{p}$ & & me & nos \\
$\mathbf{2}^{\mathbf{a}} \boldsymbol{a} \mathbf{p}$ & tú/vos & te & os \\
$\mathbf{2}^{\mathbf{}} \mathbf{b} \mathbf{p}$ & usted & lo/la/le & los/las/les \\
$\mathbf{3}^{\mathbf{o}} \mathbf{p}$ & & lo/la/le & los/las/les \\
\hline
\end{tabular}

Desde el punto de vista sincrónico, en las construcciones pasivas con se e impersonales con se, es muy difícil mantener que el marcador se constituya un pronombre reflexivo propiamente dicho. Sin embargo, es evidente que esta partícula está relacionada diacrónicamente con el pronombre reflexivo de tercera persona.

\section{Construcciones reflexivas}

El agente y el paciente de un verbo de acción-proceso corresponden al mismo participante. La valencia semántica se reduce al especificarse que el sujeto y objeto están representados por la misma entidad. Esta entidad desempeña dos roles semánticos y dos relaciones gramaticales a la vez.

Con verbos bivalentes, el paciente aparece expresado por medio de un pronombre reflexivo que cumple la función de objeto directo.

(1) Juan no se rasuró hoy.

(2) Ya quiero levantarme de aquí.

Con verbos trivalentes, el recibidor, expresado también por un pronombre reflexivo, desempeña la función de objeto indirecto. 
(3) $\quad$ Me regalé un viaje al extranjero.

(4) José Alberto se dio una lección a sí mismo.

Las predicaciones reflexivas pueden ser expresadas por medio de tres estrategias lingüísticas.

\section{a. Estrategia morfológica:}

Esta consiste en la utilización de pronombres reflexivos clíticos que son correferenciales con el sujeto, como sucede en las oraciones (1), (2), (3) y (4).

Como se ha dicho, los pronombres reflexivos clíticos son idénticos a los pronombres personales clíticos no reflexivos en algunas de las personas gramaticales ( $1^{\circ}$ y $2^{\circ} a$ personas), pero distintos en otras $\left(2^{\circ} b\right.$ y $3^{\circ}$ personas) (cf. tabla 3.1$)$.

\section{b. Estrategia analítica:}

Junto con el uso de los reflexivos clíticos, se emplean también pronombres reflexivos acentuados acompañados, por lo general, de la palabra mismo flexionada según el género y número del sujeto.

(5) Hay que preguntarnos a nosotras mismas qué hacer.

(6) Es mejor hablar primero de mí mismo.

(7) ¿Ustedes no se han visto a ustedes mismos en un espejo?

(8) ¿Ustedes no se han visto a sí mismos en un espejo?

Los reflexivos acentuados son totalmente idénticos a los pronombres personales acentuados que funcionan como sujetos, en un estilo más coloquial (cf. 7 frente a 8).

En un estilo más formal, los reflexivos acentuados difieren de los pronombres personales acentuados al igual que lo hacen los pronombres clíticos, como se muestra en la tabla 4.1.

Tabla 4.1. Pronombres reflexivos acentuados

\begin{tabular}{lccc}
\hline & & singular & plural \\
\hline $\mathbf{1}^{\mathbf{o}} \mathbf{p}$ & & mí & nosotros \\
$\mathbf{2}^{\mathbf{o}} \boldsymbol{\mathbf { p }}$ & tú/vos & tí/vos & vosotros \\
$\mathbf{2}^{\mathbf{o}} \boldsymbol{b} \mathbf{p}$ & usted & sí/usted & sí/ustedes \\
$\mathbf{3}^{\mathbf{0}} \mathbf{p}$ & & sí/él/ella & sí/ellos/ellas \\
\hline
\end{tabular}

\section{c. Estrategia léxica:}

Esta consiste en utilizar un verbo de valencia semántica 2 con una valencia gramatical 1, al omitirse el paciente de la cláusula reflexiva. Hay que señalar que esta estrategia no se emplea muy comúnmente en la expresión de predicaciones reflexivas, como sucede en otras lenguas, aunque sí ocurre esporádicamente.

(9) Todos esperábamos mientras ella bañaba. (Canal Infinito, 16/07/2003)

(10) El objetivo es defender el derecho a manifestar. (CNN en español, 09/06/2003)

(11) También alojo en una pensión. (TV Chile, 17/05/2003)

Todos los verbos subrayados de las oraciones anteriores son semánticamente bivalentes, pero gramaticalmente aparecen como intransitivos a pesar de tratarse claramente de verbos de acción-proceso. 
Los verbos reflexivos se suelen clasificar en tres tipos: los propios, los inherentes y los opcionales.

\section{a. Verbos reflexivos propios:}

Se trata, prototípicamente, de verbos de acción-proceso que son semánticamente bivalentes. En ellos, se puede distinguir, bastante claramente, un agente y un paciente que se corresponden con un sujeto y un objeto respectivamente. Las construcciones con este tipo de verbos constituyen los únicos verdaderos casos de reflexivas en las que el agente y paciente se funden en uno solo.

En estos casos, el verbo reflexivo propio se puede emparejar con un verbo típicamente transitivo que es idéntico a aquel y que se distingue solamente por la presencia de un pronombre reflexivo, como en los siguientes casos: bañar/bañase, levantar/levantarse, peinar/peinarse.

(12) Carmen levantó al bebé de la silla.

(13) La muchacha se levantó de la silla.

c. Verbos reflexivos opcionales:

Se trata de verbos prototípicamente monovalentes que, por lo general, son de acción o de proceso. Se relacionan con verbos intransitivos que pueden emplearse o no con un pronombre reflexivo, como reír/reírse, olvidar/olvidarse, desayunar/desayunarse, morir/ morirse.

(14) Un amigo mío murió de un ataque cardíaco.

(15) Ya todos mis tíos se murieron.

(16) ¿Qué querés desayunar hoy?

(17) Todavía no me he desayunado nada.

Está claro que, en todos los casos en que es utilizado, el pronombre reflexivo enfoca la atención sobre el único participante que implica el verbo monovalente. Este aparece representado como el sujeto de la cláusula y corresponde o bien a un agente, con verbos de acción (17), o bien a un paciente, con verbos de proceso (15).

Por medio de la operación de reflexivización, este participante se repite como un argumento de objeto. Esto significa, en el fondo, una degradación del participante, puesto que este aparece entonces categorizado como un argumento menos relevante en la cláusula. Es decir, el agregar un nuevo argumento de objeto directo (que prototípicamente categoriza pacientes) que sea correferencial con el sujeto (que prototípicamente categoriza agentes) indicaría que el único participante a nivel semántico se comporta también como un paciente, y que, por tanto, el evento carece de un verdadero instigador voluntario.

De esta forma, la diferencia en el uso un verbo intransitivo, como en (18) y (20), y uno pronominal, como en (19) y (21), reside en enfatizar, con este último, el sentido anticausativo de la predicación.

(18) El gato cayó parado. (Cf. * El gato se cayó parado)

(19) Rubén se cayó de la cama. (Cf. ? Rubén cayó de la cama) 
Un ejemplo paralelo se puede encontrar al comparar (20) y (21).

(20) ¿Cuántas personas murieron en el Titanic? (Cf. ? ¿Cuántas personas se murieron en el Titanic?)

(21) Me estoy muriendo de hambre. (Cf. ? Estoy muriendo de hambre)

Resulta interesante pensar que quizá el uso de pronombres clíticos con verbos de proceso como morirse, caerse y dormirse, provenga de seguir el modelo que ofrecen los verbos medios que igualmente enfatizan el carácter anticausativo del verbo (cf. apartado 6).

c. Verbos reflexivos inherentes:

Se trata de verbos semánticamente monovalentes, que son de acción, tales como arrepentirse, jactarse, atreverse. Estos verbos reflexivos carecen de una contraparte que sea formalmente un verbo transitivo o intransitivo. Esto significa que no existen en español, en principio, los verbos arrepentir, jactar o atrever.

(22) Yo nunca me arrepiento de nada.

(23) * ¡Arrepiente tus pecados! / *AArrepiente de tus pecados!

(24) María siempre se queja de sus problemas.

(25) * Mi jefe queja sus problemas. / * Mi jefe queja de sus problemas.

Al igual que en el caso de los verbos reflexivos inherentes, por una parte, en esta construcción, se enfoca la atención sobre el participante, que es un agente, el cual ha sido categorizado como sujeto. Así, pues, también por medio de la operación de reflexivización se enfatizaría el carácter anticausativo de la construcción al degradar al agente a un argumento de objeto directo.

Además, por otra parte, estas construcciones con verbos reflexivos inherentes contienen los llamados complementos verbales (de nada, de sus problemas), los cuales constituyen adyacentes que van introducidos por una preposición, pero cuya relación semántica con el verbo es más relevante que la que establece un adyacente que es un simple complemento circunstancial (cf. Ross 1982: 73-9). Los participantes que introducen los complementos verbales, aunque ocurren generalmente con verbos de acción, como soñar (con), son muy afines a los pacientes. Algunas veces, incluso, estos participantes se categorizan como objetos directos de la cláusula.

(26) Ayer soñé con mis abuelos. (con mis abuelos = complemento verbal)

(27) Yo siempre sueño cosas bonitas. (cosas bonitas = objeto directo)

Es verdad que no se trata de frases preposicionales que representan simplemente complementos circunstanciales tanto porque formalmente la preposición asociada obligatoriamente al verbo es una particular, como porque sintácticamente los complementos verbales pueden ser representados, algunas veces, por pronombres clíticos de objeto directo.

(9) Yo te $\underline{\text { sueño }}$ cada noche. (cf. Yo sueño con vos cada noche.)

(10) Nunca te he dejado de pensar. (cf. Nunca he dejado de pensar en vos.)

Por ello, se puede afirmar que estas cláusulas en las que aparecen los verbos reflexivos inherentes son ciertamente instancias de construcciones antipasivas (cf. apartado 8), las cuales tienen como propósito degradar al paciente de la oración convirtiéndolo en un adyacente. 


\section{Construcciones recíprocas}

Estas construcciones son muy afines tanto semántica como gramaticalmente con las reflexivas, en español y en otras lenguas. Los participantes son, a la vez, agentes y pacientes del evento que predica un verbo de acción-proceso.

Las construcciones recíprocas reducen la valencia semántica al indicar que los participantes actúan alternativamente como agente y paciente. Los participantes desempeñan dos roles semánticos (agente y paciente) y dos relaciones gramaticales (sujeto y objeto) a la vez.

(1) Roberto y Adriana se encontraron en el restaurante.

(2) Nidia y yo no nos soportamos.

Los llamados pronombres recíprocos son formalmente idénticos a los pronombres reflexivos clíticos (cf. tabla 3.1). Por esta razón, está claro que aquellos provienen de estos.

Con verbos bivalentes, el pronombre recíproco representa un paciente y cumple la función de objeto directo, en (1) y (2).

Con verbos trivalentes, el pronombre recíproco expresa un recibidor y desempeña la función de objeto indirecto, en (3) y (4).

(3) Los enamorados se daban unos besos apasionados.

(4) Nos enseñamos muchas cosas mutuamente.

Las predicaciones recíprocas pueden expresarse por medio de dos estrategias gramaticales.

\section{a. Estrategia morfológica:}

Esta consiste en emplear pronombres recíprocos clíticos, que como se ha dicho son idénticos a los pronombres reflexivos clíticos, en (1), (2) y (3).

\section{b. Estrategia analítica:}

Dado que los pronombres recíprocos son idénticos a los clíticos, en ocasiones, puede ocurrir una cierta ambigüedad. Por esta razón, y además probablemente por énfasis, se utiliza una forma adverbial que indica reciprocidad, junto con los pronombres recíprocos clíticos, como en (4), (5) y (6).

(5) Ellos se rascaban la espalda el uno al otro.

(6) Nos molestábamos recíprocamente.

\section{Construcciones pasivas}

En estas construcciones, el agente (instrumento o experimentador) de un verbo prototípico de acción-proceso se encuentra destopicalizado o destematizado ${ }^{3}$. Por esta razón, no se categoriza normalmente como el sujeto de la cláusula, sino que o bien se omite, o bien se degrada gramaticalizándose como un complemento circunstancial.

Además, el paciente se gramaticaliza como el sujeto de la cláusula. Desde un punto de vista pragmático, esto significa un realce de este participante.

Este sujeto, que representa entonces al paciente, es el único argumento que se relaciona con el verbo de acción-proceso, el cual funciona como un verbo intransitivo.

(1) Todos fueron llamados en orden alfabético.

(2) Todas las cartas fueron firmadas por la misma persona.

(3) Se inauguraron seis nuevas escuelas el último año. 
Las predicaciones pasivas pueden ser expresadas por medio de tres estrategias lingüísticas:

\section{a. Estrategia morfológica:}

Este tipo de construcciones se conoce normalmente como una pasiva con se. Para construirlas, se aplica una operación que consiste en introducir un marcador invariable de pasividad antes del verbo. Este marcador es la palabra se, la cual evidentemente es idéntica al pronombre reflexivo clítico de $3^{\mathbf{o}}$ persona. Desde el punto de vista diacrónico, esta partícula proviene precisamente de este pronombre de $3^{\circ}$ persona. El verbo se emplea, entonces, en su forma activa.

(4) Se necesitan dos voluntarios.

(5) Se vendieron todas las entradas.

(6) Ya se gastó todo el dinero del presupuesto.

Es evidente que, en (3), (4) y (5), el paciente funciona como el sujeto de las cláusulas, al constituir las únicas frases nominales que concuerdan en número plural con el verbo. En (6), la frase nominal todo el dinero del presupuesto es singular y puede interpretarse que está concordando con el verbo, también singular. Sin embargo, algunos gramáticos consideran que esta frase nominal no representa el argumento de sujeto, sino el de objeto directo, pues se trata ciertamente de un paciente prototípico que recibe la acción que predica el verbo. El operador ${ }^{4}$ $s e$ constituye en este caso un marcador de impersonalidad.

Cuando la frase nominal que representa al paciente está introducida por la preposición $a$, entonces con certeza se trata de un argumento que funciona como objeto directo.

(7) Se denunció al traidor.

Otro aspecto característico de las oraciones pasivas con se es que, prototípicamente, estas omiten el agente en la cláusula.

(8) ? Se firmó un acuerdo por las partes involucradas.

\section{b. Estrategia analítica:}

El paciente aparece como el sujeto de la cláusula. El verbo toma la forma de la llamada voz pasiva, que consiste en una perífrasis formada por el auxiliar ser conjugado seguido del participio del verbo principal. Este participio concuerda en género y número con el sujeto.

Por otra parte, el agente se expresa, por lo general, en forma de un adyacente introducido por la preposición por, conocido como complemento agente.

(9) Su fama era conocida por todos.

(10) México fue conquistado por los españoles en el siglo XVI.

(11) Fueron suspendidas las actividades al aire libre.

\section{c. Estrategia léxica:}

Un verbo de valencia semántica 2 aparece como un verbo de valencia gramatical 1, al omitirse el agente. El paciente de la oración concuerda con el verbo en voz activa de la cláusula. En esta, no se emplea ningún marcador de pasividad. Aunque esta estrategia tampoco es muy común en español, parece emplearse mayormente en el discurso periodístico y publicitario.

(12) Miles de personas que permanecieron aquí en vez de evacuar. (CNN en español, 30/08/2005)

(13) El programa estrena el próximo diecinueve. (Cartoon Network, 30/03/2003)

(14) El actor juramentó como gobernador. (CNN en español, 17/11/2003) 
Todos los verbos empleados en las oraciones anteriores son verbos semánticamente bivalentes y de acción-proceso. Sin embargo, se omite el agente, que es humano. En su lugar, el paciente funciona como sujeto pasivo y concuerda con el verbo.

\section{Construcciones medias}

En estas construcciones, prototípicamente, ocurre un evento que es un proceso y no una acción. Por esta razón, es muy difícil poder identificar algún agente o siquiera una fuerza. Por otro lado, el paciente que sufre el proceso se categoriza como el sujeto de la cláusula.

(1) Se agrietaron las paredes.

(2) Mi abuela se enfermó de gravedad.

(3) El barco petrolero se hundió en alta mar.

Semánticamente, la función de una construcción media es semejante a la de una pasiva con se, en el sentido de que en ambas se excluye la presencia de un agente del evento. Formalmente, sin embargo, en español, las construcciones medias parecen estar más relacionadas con las reflexivas que con las pasivas, como lo prueba el hecho de encontrar predicaciones medias expresadas por medio de otros pronombres reflexivos distintos de $s e$.

(4) El camión se volcó en la curva.

(5) Casi nos volcamos en la curva.

(6) Juan y María se empaparon de pies a cabeza.

(7) Ayer me empapé de pies a cabeza.

De la misma forma, los verbos con carácter medio están muy relacionados con ciertos verbos transitivos de acción-proceso, a los que se les ha sustraído el rasgo de la causatividad de la acción.

(8) Mi hijo quebró el vidrio.

(verbo de acción-proceso)

(9) El vidrio se quebró.

(10) La lluvia humedeció la pared.

(11) Se humedeció la pared.

(verbo de proceso)

(verbo de acción-proceso)

(verbo de proceso)

Las predicaciones medias se expresan por medio de dos estrategias lingüísticas:

\section{a. Estrategia morfológica:}

Prototípicamente, una predicación media se expresa por medio del marcador se, que es un pronombre, delante de un verbo conjugado, el cual concuerda con el sujeto constituido por un paciente. Como se ha dicho, se pueden encontrar construcciones medias en las que se emplean otros pronombres reflexivos cuando se trata de pacientes que no corresponden a una tercera persona.

(12) Los náufragos casi se ahogan.

(13) Me torcí un pie bajando las escaleras.

La oración (13), aunque formalmente es idéntica a una construcción reflexiva, en realidad tiene un claro sentido medio porque, al igual que en (5) y (7), el sujeto es un paciente y nunca un verdadero agente, sobre todo por carecer de la voluntad de actuar como un verdadero instigador del evento. Éste es más bien el objeto de un cambio de estado. Otra prueba de que estas tres oraciones no contienen predicaciones reflexivas se encuentra en el hecho de convertirse en agramaticales si se intenta construirlas empleando una estrategia analítica. 
(14) * Casi nos volcamos a nosotros mismos en la curva.

(15) * Ayer me empapé a mí mismo de pies a cabeza.

(16) * Me torcí a mí mismo un pie bajando las escaleras.

La oración (15) solo sería gramatical si se empleara en un contexto en el que fuera admisible la intencionalidad del sujeto de ducharse con la ropa puesta (tal vez a causa de un calor sofocante al llegar a una cascada de agua después de una larga caminata a través de la selva).

Ya se ha mencionado antes que aquí se considera que las construcciones medias pudieron haber servido de modelo para las reflexivas opcionales, pues en ambos casos el sujeto de la cláusula representa más un paciente que un agente propiamente dicho. Por esta razón, también ambas construcciones tienen un claro sentido anticausativo.

\section{b. Estrategia léxica:}

Se utiliza un verbo que prototípicamente es de valencia semántica 2 con una valencia gramatical 1. Por supuesto, el sujeto de la cláusula es un paciente que sufre un cambio de estado. El verbo intransitivo concuerda con el sujeto de la cláusula. Esta estrategia no es tampoco muy común en español.

(17) La estructura rompió. (Repretel Canal 6, 15/10/2007)

(18) Tres periodistas murieron cuando el vehículo en que viajaban volcó. (CNN en español, 15/05/2003)

(19) La bruma comienza a despejar. (Canal Infinito, 27/01/2006)

\section{Construcciones impersonales con $s e$}

Las construcciones impersonales excluyen la presencia del argumento de sujeto en la cláusula. Esta exclusión se debe a que el hablante desea ocultar la identidad del agente instigador del evento, la desconoce o esta no es relevante pragmáticamente.

Como estrategia morfológica, se emplea la palabra se como marcador de impersonalidad, como en las oraciones (1), (2), (3) y (4).

(1) Aquí se come bien.

(2) Se compra oro y joyas usadas.

(3) En esa escuela se enseña muy bien lenguas extranjeras.

(4) No se habla mucho en las clases de yoga.

Las cláusulas impersonales con se son muy semejantes a las construcciones pasivas con se. En ambas construcciones, se utiliza el marcador se (que, como se ha dicho, ya no funciona más como un pronombre reflexivo) como operador morfosintáctico y se omite, normalmente, el agente del evento.

Estas semejanzas son evidentes al comparar una pasiva con se (5) con una impersonal con se (6). La diferencia entre ambas radica en que, en la primera, la frase nominal (que representa al paciente) funciona como sujeto $\mathrm{y}$, en la segunda, esta frase sirve como objeto directo, lo cual es claro por la concordancia verbal.

(5) Se venden artículos de oficina (pasiva con se)

(6) Se vende artículos de oficina (impersonal con se)

Además, es interesante señalar que, desde el punto de vista diacrónico, las construcciones impersonales con se provienen de las pasivas con se. 
Las cláusulas impersonales con se presentan ciertas características particulares que las definen tanto formal como semánticamente.

En primer lugar, se hallan las cláusulas con el verbo en singular que no presentan ninguna frase nominal que pueda servir potencialmente como el sujeto, como en (1), (4) y (7).

(7) En tercer grado, se estudia bastante.

Luego, se encuentran las cláusulas con el verbo en singular (o en plural) que presentan una frase nominal que no puede ser el sujeto, por estar precedida del marcador de acusativo a. Este indica que la frase nominal funciona como objeto directo. Se trata de frases nominales que corresponden a seres humanos, definidos.

(8) Se arrestó al sospechoso del asalto.

(9) Se llamó a los implicados en la querella.

Por último, están las cláusulas con el verbo en plural, pero que tienen una frase nominal en singular, la cual, al no concordar con el verbo, no puede funcionar como sujeto, como en (2), (3), (6) y (10).

(10) Se calificó los exámenes muy consideradamente.

Como se ha dicho, en otros casos, la interpretación personal de la cláusula es inevitable.

Primeramente, están las cláusulas con verbos en plural que concuerdan con una frase nominal también plural. En este caso, aunque se trate de un paciente, la frase debe ser interpretada como el sujeto de la cláusula, como en (5) y (11). Las oraciones deben ser clasificadas como construcciones pasivas con se.

(11) Se suspendieron todos los derechos civiles.

También, se hallan las cláusulas con verbos en singular o en plural que presentan una frase nominal que funciona como el agente del evento. Por supuesto, la frase nominal debe ser interpretada como el sujeto de la cláusula. Estas oraciones se clasifican como construcciones reflexivas (12), recíprocas (13) o medias (14), según el caso.

(12) Se acomodó Juan en su sitio.

(13) Se besaron Isabel y Fernando en la mejilla.

(14) Accidentalmente, se golpeó Rafael al salir.

Por otro lado, cuando una cláusula contiene el verbo en singular y hay una frase nominal que representa el paciente de un verbo de acción-proceso, entonces esta oración puede, formalmente, ser clasificada o bien como una construcción impersonal con se (15), o bien como una construcción pasiva con se (16). En estos casos, la frase nominal puede clasificarse como el sujeto o el objeto directo de la cláusula.

(15) Ya se pagó la cuenta. (clasificación impersonal con se) OD

(16) Ya se pagó la cuenta. $\quad$ (clasificación pasiva con se) 


\section{Construcciones antipasivas o con remoción de paciente}

En una construcción antipasiva el participante que aparece degradado no es un agente (una fuerza, un instrumento o un experimentador), sino un paciente prototípico. Es decir, la operación de antipasiva tiene precisamente el efecto contrario de una pasiva: degrada al paciente en lugar de realzarlo.

Las construcciones antipasivas son comunes en las llamadas lenguas ergativas 5 . También se conocen como construcciones con remoción de paciente. Como su nombre lo indica, esta operación consiste en remover el paciente de su relación gramatical prototípica como objeto directo para convertirlo en un adyacente.

(1) Don Manuel estuvo tocando a la puerta de mi oficina.

(2) Estela se agarró de la mesa para no caerse.

Evidentemente, los participantes la puerta y la mesa son los pacientes lógicos de los verbos tocar y agarrar. Al aplicarse la operación de antipasiva, estos aparecen como objetos oblicuos, frases preposicionales con valor circunstancial en (1) y (2), y no como objetos directos, como lo hacen en (3) y (4).

(3) Don Manuel estuvo tocando la puerta de mi oficina.

(4) Estela agarró la mesa para no caerse.

Para expresar predicaciones antipasivas, se utilizan dos estrategias lingüísticas:

\section{a. Estrategia morfológica:}

Esta consiste en categorizar el paciente de un verbo bivalente de acción-proceso como una frase preposicional con valor circunstancial, como sucede en los ejemplos (1) y (5).

(5) Quisiera decirte de mi amor. (cf. Quisiera decirte mi amor.)

\section{b. Estrategia analítica:}

En este caso, el paciente del verbo bivalente de acción-proceso se categoriza, igualmente, como un adyacente. Pero, además, el verbo transitivo se convierte en reflexivo, agregándose entonces un pronombre reflexivo que es correferencial con el sujeto de la cláusula, como ocurre en los ejemplos (2) y (6).

(6) El Llanero Solitario se montó en su caballo y se alejó. (cf. El Llanero Solitario montó su caballo y se alejó.)

Es evidente que existe, entonces, una correlación entre las operaciones que sirven para formar construcciones reflexivas con verbos inherentes y construcciones antipasivas.

(7) Marina no se atrevió a nada.

(8) Me abstuve de manifestar mi opinión.

Aparte de ser reflexivos inherentes, los verbos de las oraciones anteriores tienen la característica de exigir la presencia de un complemento verbal.

En las construcciones antipasivas (y también en las construcciones con verbos reflexivos inherentes, las cuales aquí se considera que son un tipo de antipasivas), la operación que degrada al paciente para convertirlo en un adyacente permite, precisamente, que el agente de la cláusula ocupe el lugar de objeto directo que ocuparía el paciente. Este cambio en el caso sufrido por el agente (SUJETO > OBJETO DIRECTO > OBJETO OBLICUO) sigue perfectamente la jerarquía relaciones gramaticales propuesta por Comrie (1981:170) para el caso gramatical del predicador del efecto (causee) (Cleopatra, en los ejemplos) en las construcciones causativas 
cuando el verbo es intransitivo (huir, en los ejemplos) en el predicado del efecto, tal como se nota al comparar (9) y (10).

(9) Octavio hizo que Cleopatra huyera a Egipto.

SUJ

(10) Octavio la hizo (a Cleopatra) huir a Egipto.

OD OD

Por ello, como se ha dicho, la operación de antipasiva comporta también una degradación del agente, al presentarlo, entonces, como un argumento de objeto directo, el cual prototípicamente categoriza pacientes.

\section{Conclusiones}

Como se ha visto, todas las operaciones de ajuste de valencia descritas anteriormente tienen como finalidad la destransitivación de la cláusula. Desde el punto de vista semántico, esta destransitivación se logra fusionando en un mismo argumento al agente y al paciente (reflexivas propias, recíprocas), degradando al agente (reflexivas opcionales, reflexivas inherentes, pasivas con $s e$, impersonales con se, medias, antipasivas) o degradando aún más al paciente (reflexivas opcionales, antipasivas). Desde la perspectiva puramente formal, en todas las construcciones mencionadas, se utiliza una estrategia morfológica idéntica: el uso de pronombres reflexivos clíticos o de una partícula igual al pronombre reflexivo clítico de $3^{\circ}$ persona (se). Esto quiere decir que, en español, existe una clara tendencia a utilizar la misma estrategia formal para expresar un idéntico significado: que la cláusula se ha destransitivado.

Se supone que estas cláusulas se relacionan diacrónicamente. En primer lugar, hay que señalar que todas las construcciones están basadas en el modelo que ofrecen las construcciones reflexivas propias. Por supuesto, la forma de estas construcciones se remonta al latín, en donde se pueden encontrar los pronombres reflexivos clíticos de forma casi idéntica.

En el español medieval, desde sus orígenes, podemos encontrar construcciones reflexivas propias. En el Poema de Mío Cid (probablemente del siglo XII), este tipo de construcciones predominaban en cantidad sobre otras construcciones que aparecen también con pronombres reflexivos, como las recíprocas, las reflexivas opcionales, reflexivas inherentes, pasivas con se y medias. En este texto no aparecen construcciones impersonales con se ni antipasivas propiamente dichas. Las construcciones impersonales con se con una frase nominal provienen de las pasivas con se. La primeras eran simplemente consideradas formas vulgares y descuidadas de las segundas por los gramáticos normativos (Alcina \& Blecua 1975: 922). De hecho, la Real Academia Española mantuvo esta postura hasta $1973^{6}$ cuando las incluye en su clasificación oracional por primera vez en el Esbozo de una gramática de la lengua española.

\section{Bibliografía}

Alcina, Juan y José Blecua. 1975. Gramática Española. Barcelona: Ariel.

Comrie, Bernard. 1981. Language universals and linguistic typology. Chicago: University of Chicago Press. 
Payne, Thomas. 1997. Describing morphosyntax. A guide for field linguistics. Cambridge: Cambridge University Press.

Real Academia Española. 1771. Gramática de la lengua castellana. (Edición facsimilar) http:// www.cervantesvirtual.com/servlet/SirveObras/rae/57915175105571384100080/index.htm.

1931. Gramática de la lengua española. Madrid: Espasa Calpe.

1973. Esbozo de una gramática de la lengua española. Madrid: Espasa Calpe

Ross, L. Ronald. 1982. Investigando la sintaxis del español. San José: Editorial Universidad Estatal a Distancia.

Van Valin, Robert y Randy LaPolla. 1997. Syntax: Structure, meaning and fuction. Cambridge: Cambridge University Press.

Wilson, Jack. 1985. "La gramática de los casos del español”. Revista de Filología y Lingüística de la Universidad de Costa Rica. 11 (1): 67-98.

\section{Notas}

1. Los términos gramaticalización y categorización se utilizan aquí como sinónimos. La gramaticalización consiste en la marcación morfológica o sintáctica sistemáticas de una categoría linguiística.

2. La operación de pronominalización cero o de anáfora cero consiste en la omisión de sujeto de la cláusula por razones pragmático-discursiva.

3. El tópico o tema constituye el hilo conductor del discurso.

4. El término operador designa un morfema o una combinación de ellos que representan una operación gramatical.

5. A diferencia de las lenguas de tipo acusativo como el español, el inglés o el latín, en las lenguas ergativas el sujeto de un verbo intransitivo y el objeto directo de un verbo transitivo se categorizan de la misma forma, mientras que se diferencian formalmente del sujeto de un verbo transitivo. Evidentemente, se trata de lenguas que privilegian las nociones de agente y paciente por encima de las de sujeto y predicado.

6. La edición anterior de la gramática de la RAE de 1931 (que estuvo vigente hasta 1973) indica que las construcciones impersonales con se con una frase nominal pecan contra la sintaxis (p. 259). En la primera edición de la gramática de la RAE de 1771, no se consigna ni siquiera la existencia de este tipo de construcciones (cf. pp. 41-2). 
